\title{
RELIABILITY ANALYSIS OF SEMI-AUTOMATIC TRAIN DOOR SYSTEMS IN SERVICE ON TODAY'S ROLLING STOCK OF THE SNCB
}

\author{
W. Van der Gucht ${ }^{1}$, D. Vanwalleghem ${ }^{1}$, H. Bonne ${ }^{2}$, W. Eeckhout ${ }^{2}$, W. De Waele ${ }^{3}$, P. De Baets ${ }^{3}$ \\ ${ }^{1}$ Ghent University, Belgium \\ ${ }^{2}$ SNCB, Belgium \\ ${ }^{3}$ Ghent University, Laboratorium Soete, Belgium
}

\begin{abstract}
This article analyses the reliability of semi-automatic train door systems that are in use on today's rolling stock of the SNCB. For the analysis several databases of the SNCB concerning both operation and maintenance were thoroughly screened. These databases are briefly explained and scaling factors are applied to compare the performance of different series of rolling stock relative to each other. Conclusions are made out of the available data.
\end{abstract}

Keywords Reliability analysis, rolling stock, SNCB, train door systems

\section{INTRODUCTION}

The National Railway Company of Belgium (SNCB) [1] experienced that malfunctioning of the entrance doors during the operation of passenger trains is one of the top elements that cause delays. Furthermore, entrance doors can be a source of safety accidents with passengers and/or train crew. In order to understand the source of these problems, a master thesis is performed (at Ghent University in cooperation with the SNCB) on the reliability of train door systems. The purpose of this master thesis is to analyse the reliability and safety performance of different semi-automatic pneumatic door systems in service on the rolling stock of the SNCB. The SNCB deploys different types of rolling stock (e.g. hauled trains, push-pull trains, Electric Multiple Units and Diesel Multiple Units). Each series of rolling stock is referred to with its own abbreviation, found in references [2-4]. Note that EMUs and DMUs consist of multiple coaches with own traction facilities.

The master thesis will also study a reference case on an AM75-77 EMU, shown in Figure 1. This EMU will be modernised in the near future and one of the goals of the master thesis is to give well-founded advice for the optimisation of its door system. This article will quantify the reliability of the door systems based on the already available data at the SNCB.

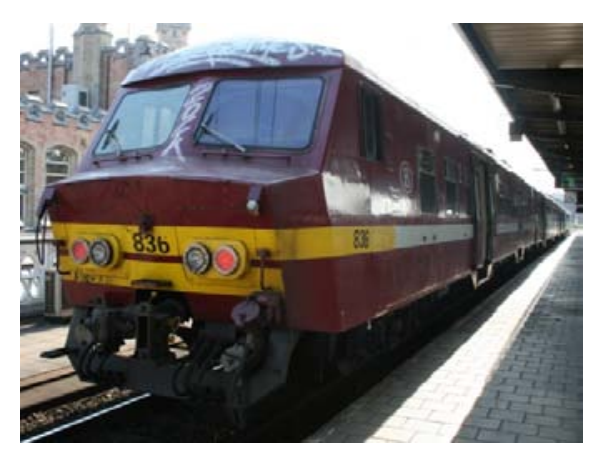

Figure 1. An AM75-77 EMU

\section{ENTRANCE DOOR SYSTEMS}

\subsection{Different train door systems in service}

All train door systems in service on the rolling stock of the SNCB are semi-automatic and electropneumatically steered. The different systems can be classified based on their kinematics.

FOLDING DOORS, shown in Figure 2.

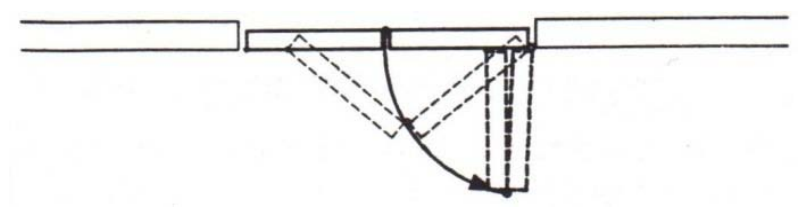

Figure 2. Kinematic principle of folding doors

Folding doors are the oldest type of semi-automatic doors in service. They are not suited for speeds above $140 \mathrm{~km} / \mathrm{h}$. 
SWING PLUG DOORS, shown in Figure 3.

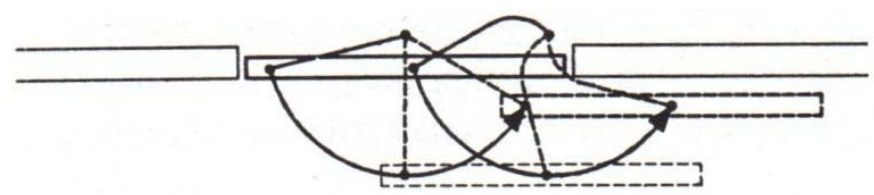

Figure 3. Kinematic principle of swing plug doors

This type is implemented on AM80-83 EMU and HV M4m, HV M5(m) coaches.

Swing plug doors have a mechanically robust design. However, a violation of the gauge of the infrastructure can occur when they are opened while the train is running in service.

SLIDING PLUG DOORS, shown in Figure 4.

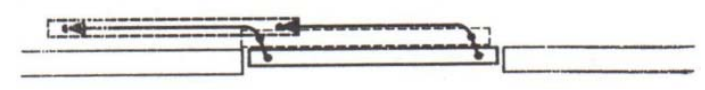

Figure 4. Kinematic principle of Sliding plug doors

This type is implemented on AM75-77, AM86-89 AM96 EMU, AR41 DMU and HV I6, HV I10, HV I11, HV M6 coaches. Sliding plug doors are the most elegant looking doors but are harder to adjust in maintenance. Even during their opening, they do not violate at any time the gauge of the infrastructure.

As mentioned all entrance doors are electro-pneumatically steered. However, two different technologies are used to handle the electric steering.

ReLAY TECHNOLOGY, used in older series and implemented on AM62-79, AM75-77, AM80-83, AM86-89 EMU and HV I6, HV I10, HV M4m, HV M5(m) coaches.

the USE of (AN) Electronic Control Unit(s), used in modern series and implemented on AM96 EMU, AR41 DMU and HVI11, HV M6 coaches.

\subsection{Scaling factors}

Before starting an analysis on the reliability of the train door systems, we figured out a way to compare the different types. This is necessary because all data we found provide absolute figures. First of all it is necessary to look to these absolute counts, because it means that you can reduce the overall amount of door problems significantly when improving the reliability of the door system that causes most of the problems. However, when comparing different train door systems one needs to consider parameters other than just the number of coaches in use of a series.

For that reason, we developed two scaling factors for every series to compare the relative amounts of data with each other.

The first scaling factor is one that is very often used by the SNCB and is based on the average amount of kilometres that a coach of a series travels during one month. Its mathematical expression is given by eq. (1).

$$
\frac{\left(\text { Mean \# Coaches.Mean \# } \# \frac{K m}{\text { Coach }}\right)_{\text {of all ser }}}{\left(\# \text { Coaches }: \frac{K m}{\text { Coach }}\right)_{\text {one series }}}
$$

The second scaling factor is one that is created by ourselves and is based on an estimation of the total number of door movements of a train series a day. Its mathematical expression is given by eq. (2).

$$
\frac{\text { (Mean Theoretical \# Door cycles) of all ser }}{\text { (Mean Theoretical \# Door cycles) }}
$$

When the total amount of incidents or problems is multiplied by the appropriate scaling factor for each series, data can be compared. 
The numbers used to calculate our scaling factors are given by Table 1.

\begin{tabular}{l|c|c|c} 
Series & \# Coaches & $\begin{array}{c}\text { \# Km/Coach } \\
\text { (one year) }\end{array}$ & $\begin{array}{c}\text { Theoretical \#Door Cycles } \\
\text { (2 days) }\end{array}$ \\
\hline AM 62-79 & 585 & 93.486 & 287.656 \\
\hline AM 80-83 & 417 & 146.746 & 183.897 \\
\hline AM 75-77 & 176 & 123.676 & 93.016 \\
\hline AM 96 & 360 & 213.011 & 117.197 \\
\hline HV 16 & 78 & 89.732 & 12.324 \\
\hline HV I10 & 93 & 63.610 & 11.036 \\
\hline HV I11 & 163 & 306.644 & 36.981 \\
\hline HV M4m & 575 & 90.491 & 126.120 \\
\hline HV M5(m) & 130 & 47.535 & 23.997 \\
\hline HV M6 & 447 & 137.607 & 162.973 \\
\hline AM86-89 & 102 & 92.117 & 49.470 \\
\hline AR 41 & 185 & 94.574 & 59.539
\end{tabular}

Table 1. Data used to derive scaling factors

\section{COLLECTION OF DATA}

\subsection{Point of view}

Any analysis on the reliability and safety of train door systems needs to consider two domains, the commercial operation and the maintenance. This is necessary because a train door system can perform very well during operation in terms of reliability and safety but with high costs in maintenance. For that reason, the different available databases at the SNCB-group are divided according to these two domains.

\subsection{Points of attention}

The major problem when performing an analysis of train door systems is to collect complete information.

A first challenge is that a train does not stand still. The malfunctioning of a train door can occur anywhere on the railroad network so maintenance personnel cannot get there immediately to make their findings about what went wrong. As an analyst you have to focus on the data of the different following-up systems (of the SNCB) and the testimonials of the train crew. Furthermore, it was only in the early 90's that rolling stock was equipped with a diagnostic system for entrance doors. However no permanent follow-up of the data from these diagnostic systems is done.

A second challenge lies in the fact that the maintenance of the trains, done by SNCB Technics [5], is performed at several maintenance sites across the railroad network. Although the maintenance rules for all the sites are the same, they all have their own interpretations and techniques. For that reason one has to pay attention when comparing maintenance data of several maintenance sites.

A third challenge is the split-up of the SNCB in 2005 in order to meet European legislation [1]. This split-up caused that every division (the operator and the infrastructure manager) wants to manage its own data and tracking system. This leads to a situation in which a 'marriage' between operation and maintenance data is difficult.

A fourth challenge is that historically at the SNCB, the follow-up of EMU, DMU and coaches are different because they have other organisations in charge of maintenance. The non-uniformity in data channels makes the analysis of (similar) train door systems on the SNCB's rolling stock more difficult.

We also have to note that the malfunctioning of train doors is often only the visible symptom of a 'disease'. E.g. a malfunctioning static inverter can cause malfunctioning doors and will thus be wrongly reported as a door. This phenomenon is inevitable and must be kept in mind when analysing train door system problems.

\subsection{Databases analyzed}

As already mentioned, the data(bases) about the follow-up of door problems will be divided into two domains.

As for the operation, which affects the passengers directly, we analysed four different databases: 
'Database Infrabel direction Network' This database keeps record of reports in which all the incidents and accidents that caused a delay of more than five minutes are (briefly) described. It is published as a text document by the direction Network of Infrabel which manages the Belgian railway infrastructure [1]. This document is internally referred as 'de Gazet' and is distributed every working day.

'Database operator SNCB - D43' is a database of complaint documents, filled in by a train attendant, to report an accident or technical failure which affects the safety, passenger comfort or regularity.

'Database operator SNCB - SMS-Averij' is a database based on SMS texting done by a train attendant. This SMS-tool allows a train attendant to report a little accident or technical failure which does not affect the safety, passenger comfort or regularity.

'Database operator SNCB - SafeTrain' is a database that manages all safety-incidents during Belgian railway operation. It was founded to inform a department of the Belgian government.

As for maintenance, we analysed two databases:

'Database operator SNCB - MARS' which stands for MAintenance Rolling Stock is a database that manages maintenance tasks and the (spare) parts of the SNCB's rolling stock.

'Database operator SNCB - Warranty tracking of M6-coaches' is a database unique for the 492 M6 double deck coaches (Figure 5) which are entering the final stage of production and delivery. The database contains all the information of the warranty follow-up of the SNCB's new double deck coaches by their manufacturer Bombardier-Alstom.

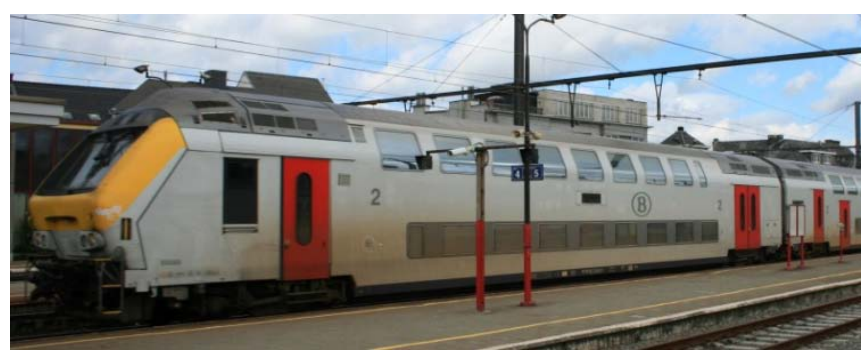

Figure 5 A M6 double deck coach

\subsection{Fault categories}

Different types of faults occur (e.g. a single door can refuse to open or close, all the doors refuse to close,..) and they have different consequences (e.g. a (serious) delay, a cancelled train, a passenger or a member of the train crew being hurt). Therefore it is important to consider fault categories. However not being done in the first part of the master thesis, this issue will be incorporated in the final master thesis text.

\subsection{Evaluation period}

We opted for an evaluation period of one year starting from July $1^{\text {st }} 2009$ till June $30^{\text {th }} 2010$. This time frame is used for every database analysed, unless being stated otherwise.

\section{OPERATIONAL DATA ANALYSIS}

\subsection{Database Infrabel direction Network}

As mentioned earlier, Infrabel's database is a text document so it needs to be manually analysed. A total of 611 incidents concerning entrance doors were reported. Graph 1 shows the total amount of incidents for each series listed in Infabel's database during the chosen time frame. The graph clearly shows that the M6 coaches and the AM62-79 EMU's cause more delays longer than 5 minutes due to door incidents. 


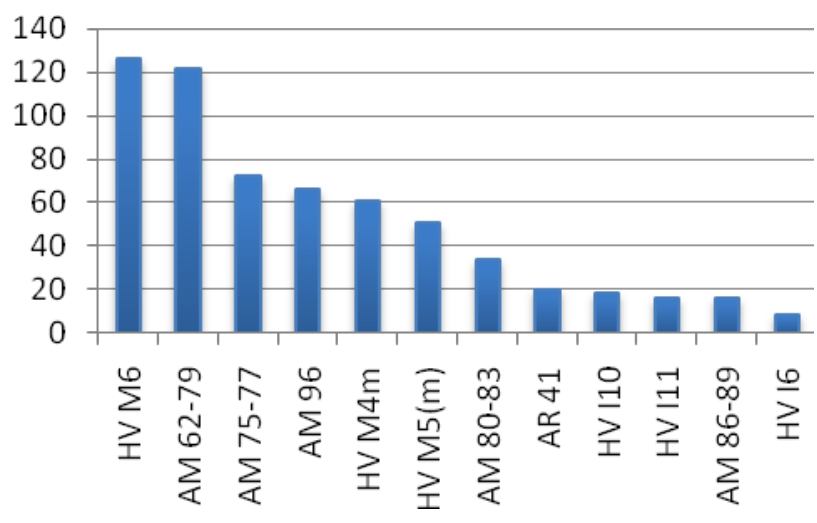

Graph 1. Number of door incidents for each type of train reported in Infrabel's database (period 01/07/2009 until 30/06/2010 and without scaling)

Graph 2 shows the number of minutes of delay caused by each train series due to door problems over the same period. The total delay caused by door problems is 29,523 minutes (approximately 492 hours). In comparison all problems with the rolling stock accounted for a delay of 455,008 minutes in 2009 [6].

Graph 3 shows the number of cancelled trains due to door problems over the same period totalising 486 cancelled trains. This number also includes the indirectly cancelled trains. These are cancelled because another train had door problems and is blocking the track ahead or the train with door problems cannot assure its other services and so on. In comparison a total of 21,556 trains were cancelled in 2009 [6].

By evaluating Graph 2 and Graph 3 we see both HV M6 and AM62-79 coming in front again. We notice that door problems on the older AM62-79 series cause more delay but less cancelled trains contrary to the newer HV M6 series.

The AM75-77 completes the top-three despite its limited number of coaches in use.

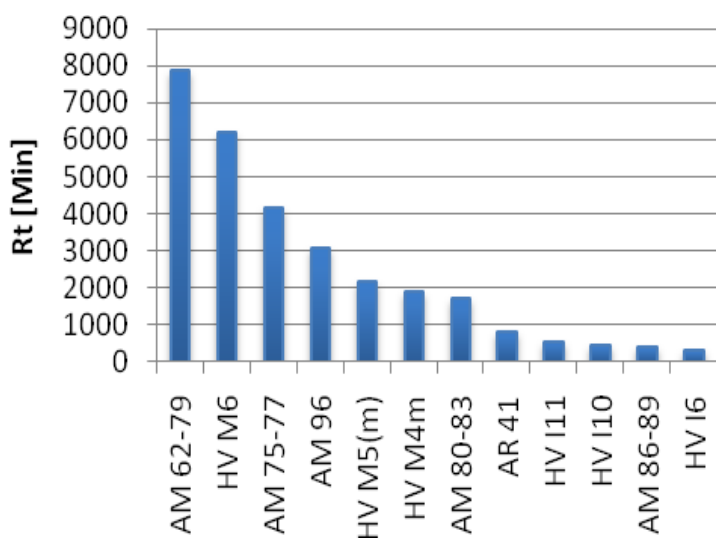

Graph 2. Number of minutes delay due to door problems (period 01/07/2009 - 30/06/2010)

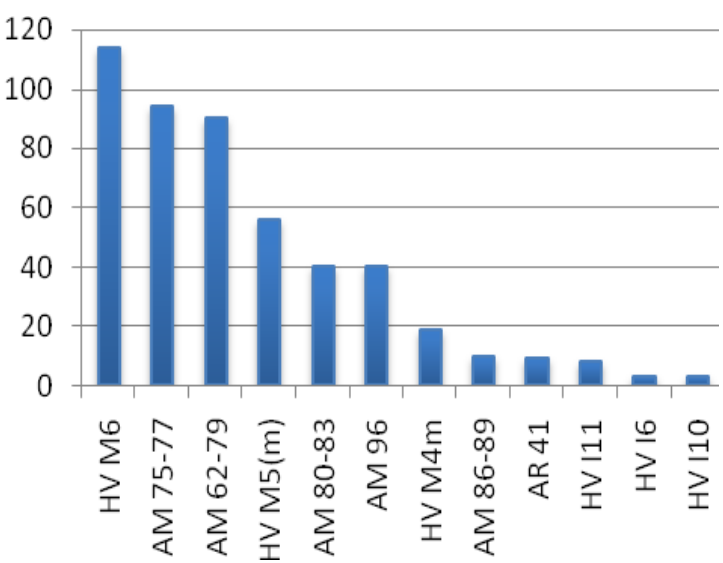

Graph 3. Number of cancelled trains due to door problems (period 01/07/2009 - 30/06/2010)

In order to compare the different train door systems we apply our two scaling factors as earlier mentioned. Graph 4 and Graph 5 show the results.

Both graphs place the HV M5(m) and the HV 110 in the top-three. These two series of coaches mostly provide enhanced supply during peak hour thus not having a lot of kilometres and door movements on their record.

Another thing that we have noticed is that with the introduction of the modernised HV M5 series, named the HV M5m, the number of door incidents reported with the HV M5 $(\mathrm{m})$ increased. Possibly there are a few growing pains concerning the door system of the HV M5m. However we did not have the possibilities to distinct whether a HV M5 or a HV M5m was involved in an incident, so we could only make an assumption. This can be subject of further investigation. 


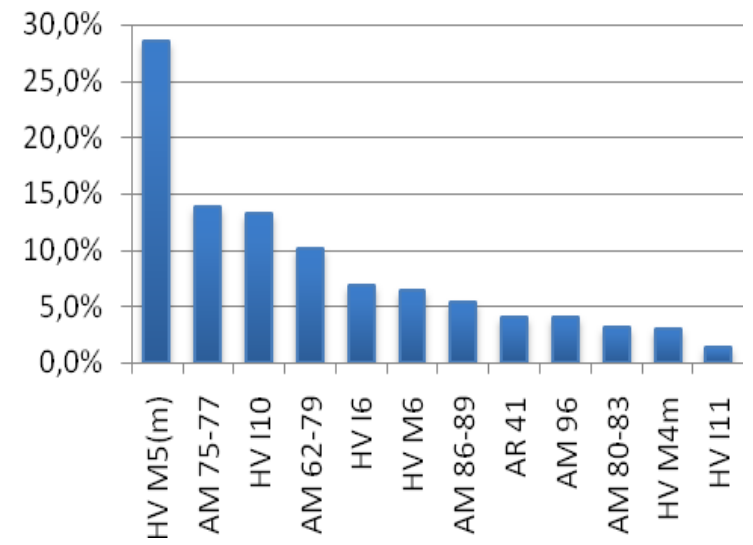

Graph 4. Relative portion of the amount of delay due to door problems for each series by scaling the absolute figures with the first scaling factor.

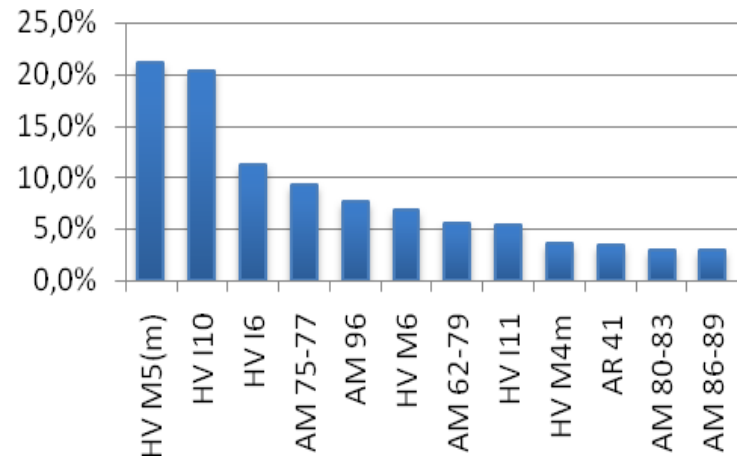

Graph 5. Relative portion of the amount of delay due to door problems for each series by scaling the absolute figures with the second scaling factor.

\subsection{Database operator SNCB - D43}

The database of Infrabel direction Network only reports incidents that cause a delay of more than 5 minutes. The 'D43' database reports all the incidents seen by the train manager during operation. Integrating both databases and taking into account the double counting of incidents, should give a more complete picture of the door reliability in operation. The integration was done over the same time period of one year. In Graph 6 the number of door incidents are shown. We found for the period mentioned a total of 1,279 incidents.

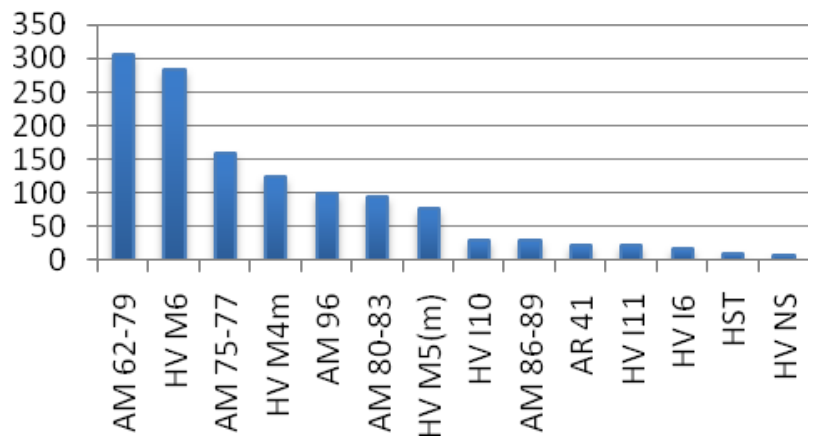

Graph 6. Number of door incidents reported by integration of two databases (period 01/07/2009 30/06/2010)

The trend seen in Graph 6 is similar as observed in Graph 1, meaning that the application of our scaling factors would give approximately the same results as in the previous paragraph.

\subsection{Database operator SNCB - SMS-Averij}

Adding the data from 'SMS-Averij' to our own big database would have given us a complete listing of all door incidents that occurred during operation for the period mentioned. However it appears that there are currently two methods used to obtain an extraction out of the 'SMS-Averij' database. The old way (Figure 6) did not allow us to obtain the desired data.

\begin{tabular}{c|c|c|c|c|c|c|c|c|c} 
OORSP : IBIS and Stat:Som \\
\hline datum & VOER & TRKS & Voorz & $\begin{array}{c}\text { OMSCHRIJVING } \\
\text { WAUW }\end{array}$ & WERK & GLDW & UIC & Trst & Teff WRKT \\
\hline $1 / 02 / 2010$ & 11704 & I10A & N & ok & $\ldots$ & $\ldots$ & $51881170004-7$ & FBMZ- & 0,5 \\
M52 &
\end{tabular}

Figure 6. Old extraction out of the 'SMS-Averii' database. 
The new one (Figure 7) fulfilled our expectations but we noticed that the system was in a start-up phase for the period requested.

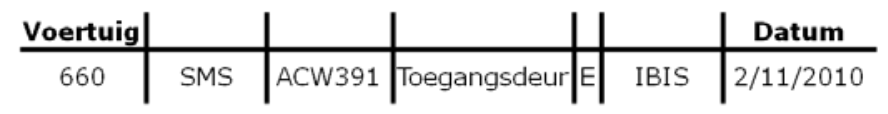

Figure 7. New extraction out of the 'SMS-Averij' database.

Therefore we asked more data and only the results of the last obtained month (November 2010) were taken into account. The number of door incidents are shown in Graph 7. When looking at the graph we see approximately the same distribution as in Graph 6 with the exception of the HV M4m which is ranked second. At this moment a possible explanation can be that the HV M4m often has more door problems which do not affect the safety, passenger comfort or regularity.

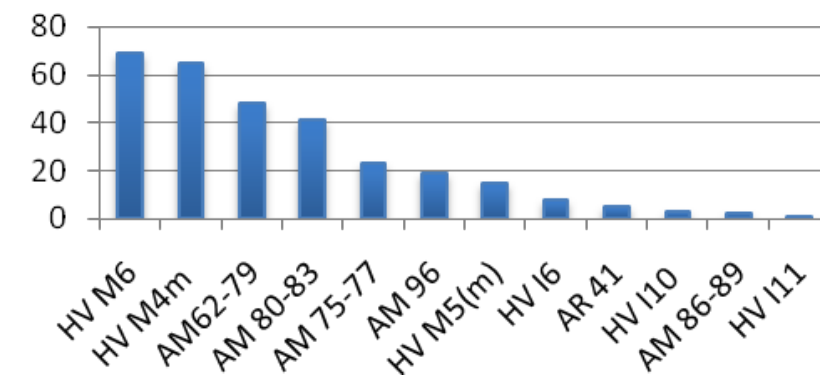

Graph 7. Number of door incidents collected from the new extraction system of 'SMS-Averii' (period November 2010)

\subsection{Database operator SNCB - SafeTrain}

The last database we analysed was SafeTrain, in which all safety problems are divided into predefined categories. This database can have some incidents in common with those found in Infrabel's database and database ' $\mathrm{D} 43$ '. The reason is that a safety problem mostly causes more than five minutes of delay and that the train attendant must always fill in a D43 when such a problem occurs.

The main reason why we wanted to investigate the safety problems related to the entrance doors is to have an idea about how safe the different train door system designs are. This is important because some series (e.g. the M6 double deck coach) have a moveable step or a folding step. These kind of steps can be made bigger because they fold away keeping the limits of the free space profile. A fixed step must be smaller to stay within the gauge of the infrastructure.

The advantage of such a folding step is that they are safer for passengers when boarding, but the mechanism can reduce the reliability when giving direct feedback to the door steering, as experienced with the HV M6.

Although we received a list stating all safety incidents that could involve the entrance doors for the requested period, we did not have the possibilities to identify which series were involved. So the potential of this database had to be left unused.

However as an alternative we searched Infrabel's database for safety related problems during passenger boarding. Table 2 contains the results.

It is clear that no significant difference can be observed between series with or without a folding step. However it is dangerous to make any profound conclusions because of the insufficient amount of data and the influence by many other factors (e.g. weather conditions while boarding, the height of the railway platform). 


\begin{tabular}{l|c|c|c} 
Type & $\begin{array}{c}\text { Number of } \\
\text { persons } \\
\text { fallen } \\
\text { between } \\
\text { train and } \\
\text { platform }\end{array}$ & $\begin{array}{c}\text { Other } \\
\text { incidents }\end{array}$ & $\begin{array}{c}\text { Folding } \\
\text { step }\end{array}$ \\
\hline AM 80-83 & 5 & 0 & Partially \\
\hline M6 & 2 & 3 & Yes \\
\hline I11 & 2 & 0 & Yes \\
\hline MS 96 & 0 & 2 & No \\
\hline M5(m) & 1 & 1 & No \\
\hline AM 62-79 & 5 & 1 & No \\
\hline MM 75-77 & 1 & 0 & No \\
\hline MW41 & 2 & 0 & No \\
\hline Total & 17 & 7 &
\end{tabular}

Table 2. Safety incidents reported in Infrabel's database (period 01/07/2009 until 30/06/2010)

\section{MAINTENANCE DATA ANALYSIS}

\subsection{Database operator SNCB - MARS: hours performed on the maintenance of entrance doors (only 4 series of EMUs)}

To get an idea about the requirements concerning maintenance for the different train door systems, we performed an analysis of the maintenance tasks database of MARS. Four series of EMUs were analysed. First the hours spend in maintenance on train doors are evaluated and shown in Graph 8. Maintenance is stated as 'unplanned' when needed to be performed due to an incident during operation.

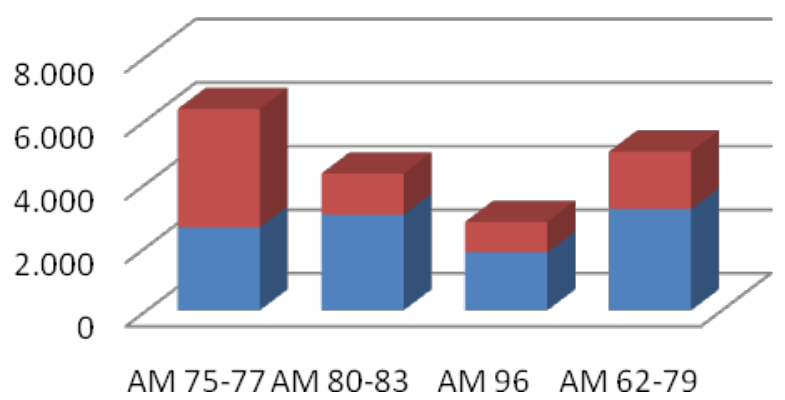

Graph 8. Hours of maintenance spend on the train door system (without scaling) (period 01/07/2009 until 30/06/2010) Legend: Blue=planned maintenance and Red = unplanned maintenance

To compare the different train door systems on the EMUs we can scale the hours in Graph 8 to obtain the hours of maintenance needed to let a door system perform 1,000,000 cycles or let a coach travel 1,000,000 kilometres. The results are shown in Graph 9 and Graph 10 respectively.

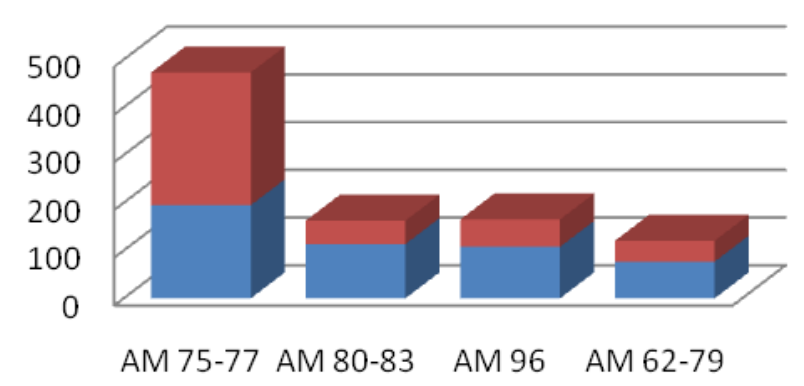

Graph 9. Hours of maintenance on the door system to let one door system perform 1,000,000 cycles. (period 01/07/2009 until 30/06/2010) Legend: Blue=planned maintenance and Red = unplanned maintenance

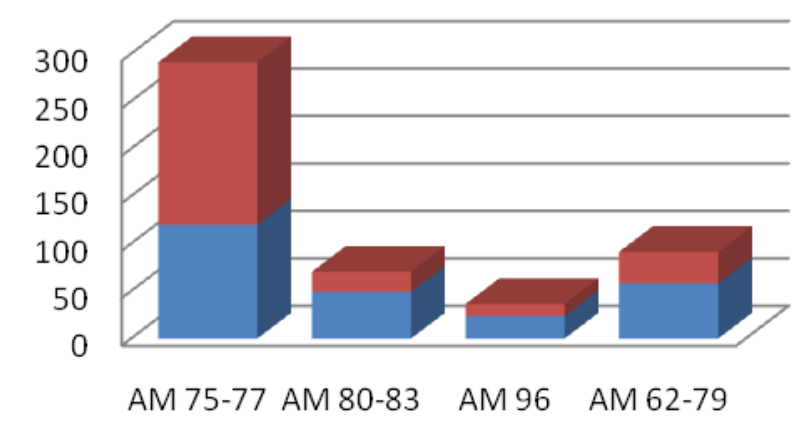

Graph 10. Hours of maintenance on the door system to let one coach travel 1,000,000 kilometres. (period 01/07/2009 until 30/06/2010) Legend: Blue=planned maintenance and Red = unplanned maintenance 
Looking at both graphs we immediately notice that the door system of an AM75-77 EMU requires up to 3 times more maintenance hours which represent a considerable cost. Another remarkable fact is the awkward spread between planned and unplanned maintenance of the door system of an AM75-77 EMU in comparison to the other EMUs. These findings offer opportunities while re-evaluating the door system and its maintenance procedures in the modernisation process of the AM75-77 EMU. By giving its design an upgrade and by revising the maintenance procedures, reduced maintenance costs could be possible. The second conclusion that can be drawn is that both reduction factors give approximately the same results (with the exception of the AM96 EMU which travels a large amount of kilometres).

\subsection{Database operator SNCB - MARS: number of maintenance tasks (EMUs+coaches)}

Based on the available data a suggestion was made to compare the number of unplanned maintenance tasks of the 4 EMUs to the number of rejections caused by door problems of 4 series of coaches. Graph 11 makes the comparison.

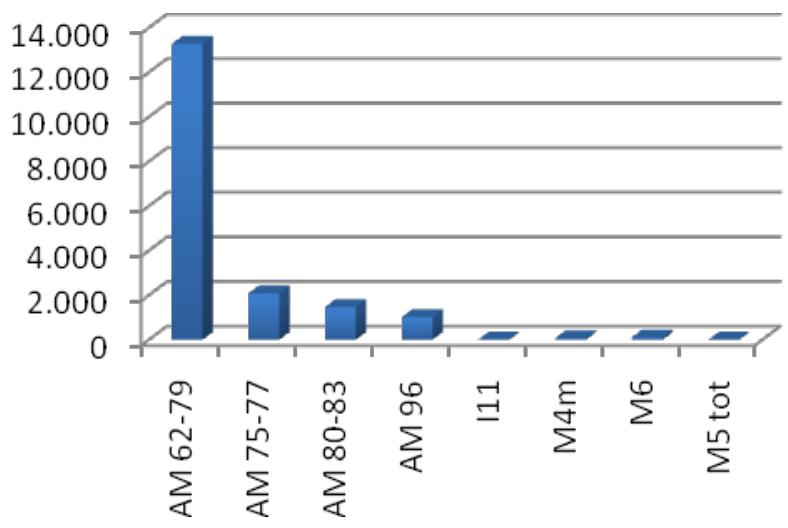

Graph 11. Number of unplanned maintenance tasks of the EMUs compared to number of rejections of coaches both due to door problems. (period 01/07/2009 until 30/06/2010)

Graph 11 has two types of highly unrepresentative data.

First, a lot of unplanned maintenance tasks for the AM62-79 are recorded while Graph 8 does not give an indication in that direction. Therefore it can be useful to examine the maintenance tasks for the AM62-79 series EMU. The AM62-79, also known as 'twins', cover a large family of EMUs divided into multiple series. When we look more in detail to these series (also see [3]), we notice that a very large amount in the unplanned maintenance tasks is coming from the AM62-65 series (Graph 12).

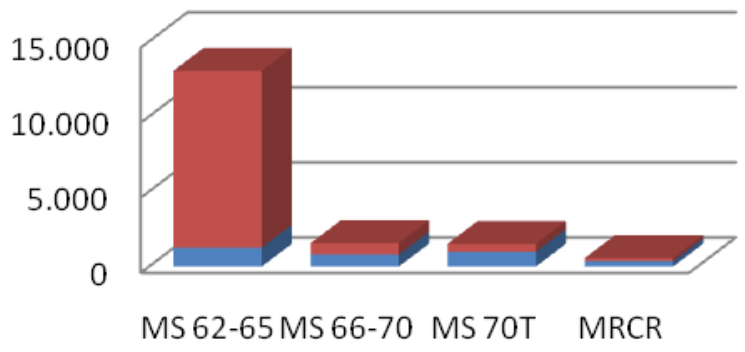

Graph 12. Number of maintenance tasks for the four series in the AM62-79 family. (period 01/07/2009 until 30/06/2010) Legend: Blue=planned maintenance and Red = unplanned maintenance

Omitting the AM62-79 from Graph 11 results in Graph 13 which gives a more detailed view for the other series.

Second, a huge difference is noticed in numbers between the unplanned maintenance tasks of the EMUs and the rejections of the coaches. This has nothing to do with the door systems of the coaches performing so much better. The only conclusion that can be drawn is that comparing the two different databases is completely meaningless. This leads to the inability to compare similar types of door systems implemented across EMUs and coaches (e.g. the door system of an AM96 EMU and an I11 coach). 


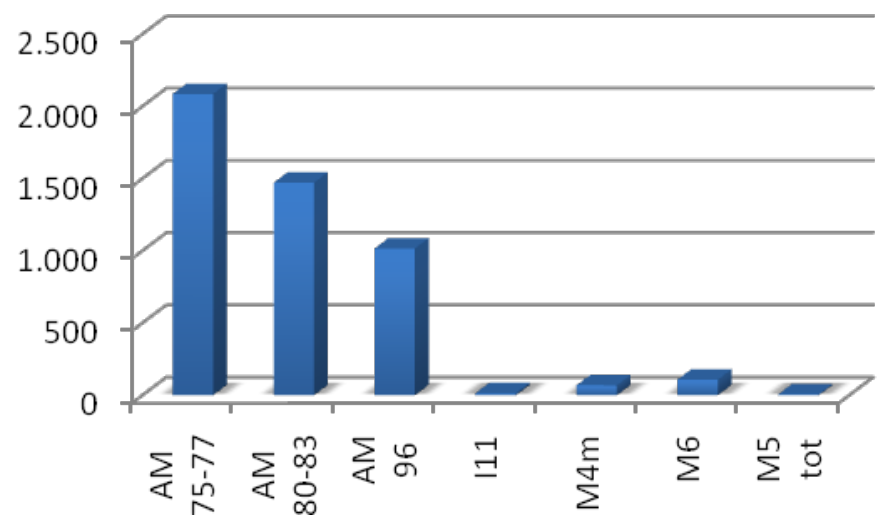

Graph 13. Number of unplanned maintenance tasks of the EMUs compared to number of rejections of coaches both due to door problems (excluding AM62-79) (period 01/07/2009 until 30/06/2010)

\subsection{Database operator SNCB - Warranty tracking of M6 double deck coaches}

One of the most complete databases available from the operator SNCB is the warranty tracking of SNCB's new M6 double deck coaches. During their warranty period every problem that occurs is mentioned and is included into the warranty tracking system. Every type of problem that occurs receives a certain predefined code. When a new problem category occurs, a new code is generated. Graph 14 and Graph 15 show the top ten ranking for the most common codes in the warranty tracking database of the 'Basic' order and the 'Option' orders of the M6 double deck coaches.

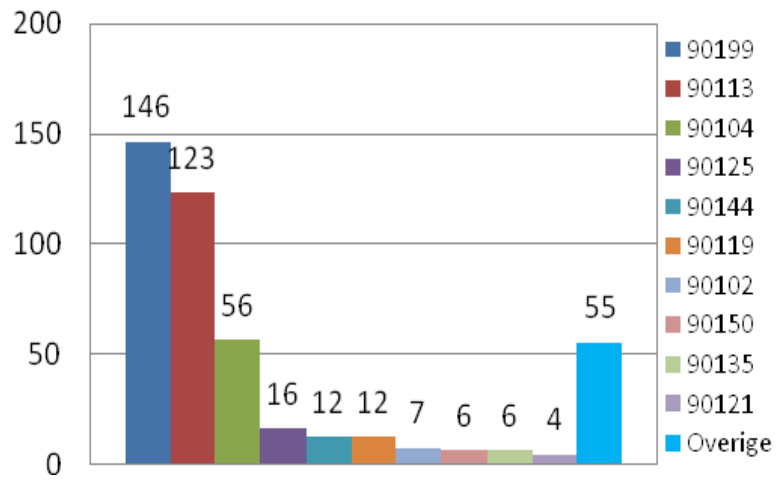

Graph 14. Top 10 of the most common codes for door problems of the first 'Basic' order of $210 \mathrm{M} 6$ double deck coaches. (period 01/07/2009 until 30/06/2010) Note: 'Overige' means 'Balance'

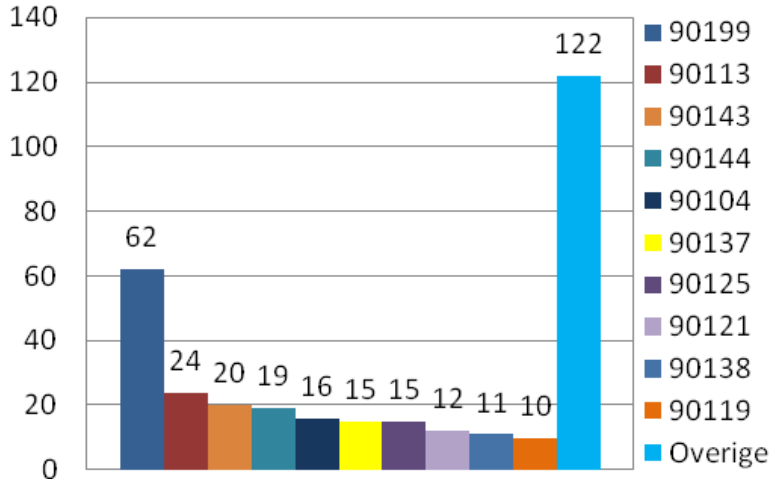

Graph 15. Top 10 of the most common codes for door problems of the 'Option' orders totalizing 282 M6 double deck coaches. (period 01/07/2009 until 30/06/2010) Note: 'Overige' means 'Balance'

Graph 14 indicates that the 'Basic' order had three types of problems that occurred most frequently. As seen in Graph 15, the 'Option' orders are more uniformly spread over all the codes. This means that the manufacturer worked on the severe problems after the delivery of the 'Basic' order. That is the reason why the last column 'Balance' of Graph 15 is that big. All problem types occurred approximately at the same rate. We can also put the numbers for the 'Basic' and 'Option' orders together an look at the monthly spread of the door problems. Graph 16 displays the result.

The follow-up of the door problems of the SNCB's new M6 double deck coach in the warranty tracking system is needed. This is proven by the statistics derived from commercial operation. It can be a tool to increase the reliability of a series of coaches that are very important due to their high capacity and expected lifetime of at least another 30 or 40 years. 


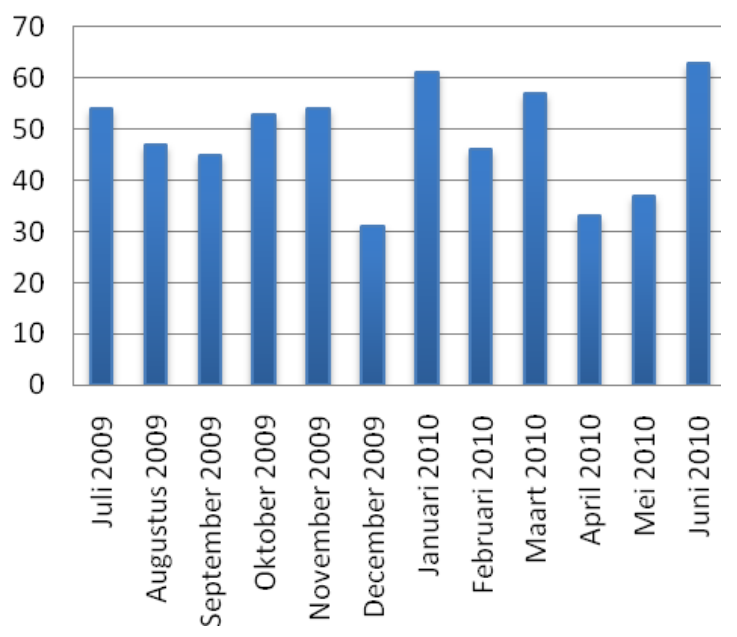

Graph 16. Monthly distribution of door problems of the 'Basic' and 'Option' orders in the warranty tracking system of the M6 double deck coaches. (period 01/07/2009 until 30/06/2010)

\section{CONCLUSIONS}

An attempt was made to analyse the reliability of the semi-automatic train door systems in use on today's rolling stock of the SNCB. The analysis enclosed both the domains of operation and maintenance. Within the limitations of the databases analysed, following conclusions can be made.

First of all the series AM62-79, AM75-77 and HV M6 face a big part of the door problems during operation. So both the oldest series of rolling stock and the newest series are affected. It has to be noticed that the HV M6 takes the lead in the cancelled trains due to door problems.

Further development of the 'SMS-Averij' tool can provide extra insights with respect to the problems concerning entrance doors.

Series that are only used as supply enhancement during peak moments tend to come on the forefront when data are scaled. Because their usage is limited, one could assume these can be ignored. However a standstill of a train due to technical problems during peak hour can lead to a bottleneck causing a lot of delay for many customers.

There is a potential of reduced maintenance costs when improving the train door system of the AM75-77 EMU during modernisation.

A warranty tracking system for the SNCB's new M6 double deck coaches provides useful technical data if applied correctly.

We can state that a simplified uniform data system for the follow-up of technical systems like train door systems is necessary in a commercial operation environment. The importance of reliable train door systems will only increase with the introduction of the Regional Express Network around Brussels and the growing number of passengers/customers the SNCB has to transport and satisfy.

After the different databases being analysed, the master thesis will mainly study the AM75-77 EMU. Therefore techniques like Fault Tree Analysis and Mean Time Between Failure will be implemented.

\section{ACKNOWLEDGEMENTS}

The authors would like to acknowledge the help of many people working at the SNCB.

\section{REFERENCES}

[1] Wikipedia, t.f.e. National Railway Company of Belgium. Available from: http://en.wikipedia.org/wiki/National_Railway_Company_of_Belgium.

[2] Neef, D.D. Voitures SNCB. Available from: http://www.belrail.be/F/fiches/car/index.php.

[3] Neef, D.D. Automotrices SNCB. Available from: http://www.belrail.be/F/fiches/emu/index.php.

[4] Neef, D.D. Autorails SNCB. Available from: http://www.belrail.be/F/fiches/dmu/index.php.

[5] SNCB. SNCB Technics. Available from: http://www.b-rail.be/corporate/F/company/destination_mieux/sncb_technics/index.php.

[6] Infrabel, N., 'Stiptheid van het treinverkeer' - Jaarverslag 2009. $20 \overline{1} 0$. 